\title{
Cognitive-behavioral therapy for insomnia: A review of 8 studies
}

Kalyan Muppavarapu, MD, MPH, Manoranjan Muthukanagaraj, MD, and Sy Atezaz Saeed, MD, MS

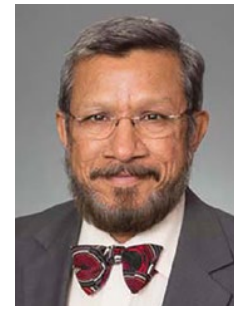

Sy Atezaz Saeed, MD

Department Editor

\section{Evidence suggests}

CBT-I might

benefit patients

with comorbid

depression, sleep

apnea, or PTSD

\section{f}

Discuss this article at www.facebook.com/ MDedgePsychiatry

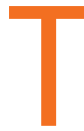
he prevalence of insomnia in the general population is approximately $6 \%$ to $10 \% .{ }^{1}$ In addition, an estimated $30 \%$ of the general population may have symptoms of insomnia without meeting the diagnostic criteria. ${ }^{2}$ As a disorder, insomnia is characterized by a persistent difficulty initiating or maintaining sleep, or early morning awakening with inability to return to sleep, that has been present for at least 3 months. Additionally, the sleep difficulties must occur at least 3 nights a week, result in impaired daytime functioning, and cause significant distress. ${ }^{1}$

Cognitive-behavioral therapy for insomnia (CBT-I) is an effective treatment, supported by several systematic reviews and meta-analyses. ${ }^{3-5}$ In the short term, CBT-I is as effective as pharmacotherapy. ${ }^{6}$ However, CBT-I is the preferred treatment for chronic insomnia, according to recommendations in European and American guidelines. ${ }^{7,8}$

Here we review 8 recent studies that examined CBT-I. These studies are summarized in the Table $e^{9-16}$ (page 41).

1. Cheng P, Kalmbach DA, Tallent G, et al. Depression prevention via digital cognitive behavioral therapy for insomnia: a randomized controlled trial. Sleep. 2019;42(10):zsz150. doi: 10.1093/sleep/zsz150.

Although CBT-I is a first-line treatment for chronic insomnia, it is underutilized in clinical practice primarily due to limited availability. Because few clinicians are certified in CBT-I, it has become necessary to develop alternative modes of delivery for CBT-I, such as fully automated, internet-delivered approaches to reach more patients with insomnia. Digital CBT-I (dCBT-I) is comparable to in-person CBT-I in improving insomnia symptoms and reducing concurrent depressive symptoms with insomnia. It is unclear if unguided, internet-delivered CBT-I is effective for achieving remission from depression or preventing depression in the long term. Chen et $\mathrm{al}^{9}$ examined the efficacy of dCBT-I in reducing and preventing depression over a 1-year follow-up.

\section{Study design}

- Participants from various centers in Southeastern Michigan were recruited between 2016 and 2017. Data was obtained from the Sleep to Prevent Evolving Affective Disorders (SPREAD) trial.

- Participants who met DSM-5 criteria for chronic insomnia disorder were randomized to dCBT-I $(n=358)$ using the Sleepio digital CBT program via the internet or to online sleep education $(\mathrm{n}=300)$.

- The primary outcome was depression, measured using the Quick Inventory of Depressive Symptomatology-Self Report

Dr. Muppavarapu is Assistant Professor, Department of Psychiatry and Behavioral Medicine, East Carolina University Brody School of Medicine, Greenville, North Carolina. Dr. Muthukanagaraj is a PGY-5 Internal Medicine/Psychiatry Resident, Department of Internal Medicine, Department of Psychiatry and Behavioral Medicine, East Carolina University Brody School of Medicine, Greenville, North Carolina. Dr. Saeed is Professor and Chair, Department of Psychiatry and Behavioral Medicine, East Carolina University Brody School of Medicine, Greenville, North Carolina.

\section{Disclosures}

The authors report no financial relationships with any companies whose products are mentioned in this article, or with manufacturers of competing products.

doi: 10.12788/cp.0040 


\section{Cognitive-behavioral therapy for insomnia: 8 Studies}

\begin{tabular}{|c|c|c|}
\hline Study & Design & Outcomes \\
\hline Cheng et $\mathrm{al}^{9}$ & $\begin{array}{l}658 \text { patients with chronic insomnia } \\
\text { from the Sleep to Prevent Evolving } \\
\text { Affective Disorders trial (RCT) were } \\
\text { randomly assigned to dCBT-I or online } \\
\text { sleep education for } 1 \text { year }\end{array}$ & $\begin{array}{l}\text { dCBT-I resulted in a significant } \\
\text { reduction in severity of depression. } \\
\text { The number of individuals who } \\
\text { reported no depression at } 1 \text {-year } \\
\text { follow-up was } 51 \% \text { higher in the } \\
\text { dCBT-I group }\end{array}$ \\
\hline Vedaa et $\mathrm{al}^{10}$ & $\begin{array}{l}181 \text { patients with chronic insomnia } \\
\text { were randomly assigned to } 9 \text { weeks of } \\
\text { unguided CBT-I or web-based patient } \\
\text { education with assessment after the } \\
\text { intervention and at } 18 \text { months }\end{array}$ & $\begin{array}{l}\text { Unguided internet-based CBT-I was } \\
\text { efficacious in maintaining effects on } \\
\text { sleep, daytime functioning, and beliefs } \\
\text { about sleep at } 18 \text { months }\end{array}$ \\
\hline Sweetman et al ${ }^{11}$ & $\begin{array}{l}145 \text { patients with OSA and chronic } \\
\text { insomnia were randomized to } 4 \\
\text { sessions of CBT-I or TAU before } \\
\text { starting CPAP therapy }\end{array}$ & $\begin{array}{l}\text { Compared with participants in the } \\
\text { TAU group, those who received } \\
\text { CBT-I were more likely to adhere } \\
\text { to CPAP (an average of } 61 \text { minutes } \\
\text { more per night) and had } 10 \% \text { higher } \\
\text { initial acceptance of CPAP, with } \\
\text { improvements in insomnia severity } \\
\text { and dysfunctional sleep-related } \\
\text { cognitions }\end{array}$ \\
\hline Asarnow et $\mathrm{al}^{12}$ & $\begin{array}{l}139 \text { patients with MDD and insomnia } \\
\text { who were receiving an antidepressant } \\
\text { were randomized to } 8 \text { weeks of CBT-I } \\
\text { or sleep education. Assessments } \\
\text { included HRSD, ISI, and a measure of } \\
\text { circadian preference (morningness vs } \\
\text { eveningness) }\end{array}$ & $\begin{array}{l}\text { CBT-I was effective for insomnia } \\
\text { regardless of circadian preference. } \\
\text { Participants with greater evening } \\
\text { preference experienced a smaller } \\
\text { reduction in HRSD scores }\end{array}$ \\
\hline Drake et $\mathrm{al}^{13}$ & $\begin{array}{l}150 \text { postmenopausal women with } \\
\text { chronic insomnia were randomized } \\
\text { to SHE, SRT, or CBT-I. Assessments } \\
\text { included ISI and sleep diaries }\end{array}$ & $\begin{array}{l}\text { ISI improvement and remission rates } \\
\text { were greater in the order of CBT-I > } \\
\text { SRT > SHE. Sleep duration was } 40 \text { to } \\
43 \text { minutes longer in CBT-I group than } \\
\text { in other groups }\end{array}$ \\
\hline Kalmbach et $\mathrm{al}^{14}$ & $\begin{array}{l}150 \text { women with new peri/post- } \\
\text { menopausal onset or exacerbation } \\
\text { of insomnia were randomized to } \\
\text { SHE, SRT, or CBT-I. Assessments } \\
\text { included ISI, sleep diaries, fatigue, } \\
\text { energy, self-reported sleepiness, work } \\
\text { productivity, and quality of life before } \\
\text { the intervention and at } 6 \text { months }\end{array}$ & $\begin{array}{l}\text { CBT-I and SRT were superior to } \\
\text { SHE for fatigue, energy, daytime } \\
\text { sleepiness, and work function. } \\
\text { The CBT-I group experienced } \\
\text { improvement in resiliency to physical } \\
\text { and emotional problems }\end{array}$ \\
\hline Peoples et $\mathrm{al}^{15}$ & $\begin{array}{l}\text { Secondary analysis of } 67 \text { cancer } \\
\text { survivors with chronic insomnia } \\
\text { who were randomized to CBT-I plus } \\
\text { armodafinil or placebo, or to SHE plus } \\
\text { armodafinil or placebo. Assessments } \\
\text { included PHQ-9 and ISI }\end{array}$ & $\begin{array}{l}\text { Immediately after the intervention, } \\
\text { participants in the CBT-I group } \\
\text { had a } 38 \% \text { greater improvement in } \\
\text { depression than those who received } \\
\text { SHE }\end{array}$ \\
\hline Harb et $a 1^{16}$ & $\begin{array}{l}108 \text { US veterans with deployment- } \\
\text { related PTSD and recurrent } \\
\text { nightmares were randomized to CBT-I } \\
\text { plus IR or CBT-I alone }\end{array}$ & $\begin{array}{l}\text { Compared to CBT-I alone, CBT-I plus } \\
\text { IR did not provide an advantage in } \\
\text { improving nightmare frequency or } \\
\text { distress }\end{array}$ \\
\hline \multicolumn{3}{|c|}{$\begin{array}{l}\text { CBT-I: cognitive-behavioral therapy for insomnia; CPAP: continuous positive airway pressure; dCBT-I: digitally delivered } \\
\text { cognitive-behavioral therapy for insomnia; HRSD: Hamilton Rating Scale for Depression; IR: imagery rehearsal; ISI: Insomnia } \\
\text { Severity Index; MDD: major depressive disorder; OSA: obstructive sleep apnea; PHQ: Patient Health Questionnaire; RCT: } \\
\text { randomized controlled trial; PTSD: posttraumatic stress disorder; SHE: sleep hygiene education; SRT: sleep restriction } \\
\text { therapy; TAU: treatment as usual }\end{array}$} \\
\hline
\end{tabular}

\section{Clinical Point \\ dCBT-I can improve depression and insomnia and has a sustained antidepressant effect}




\section{Clinical Point}

Fully-automated,
internet-based CBT-I
is efficacious in
maintaining positive
effects on sleep and
daytime functioning
for up to 18 months

(QIDS-SR-16) at 1-year follow-up. Depression incidence was also tested against insomnia treatment response.

\section{Outcomes}

- The severity of depression was significantly lower at 1-year follow-up in the dCBT-I group compared with the control group.

- The dCBT-I group showed a $51 \%$ higher remission rate than the control group at 1-year follow-up.

- The incidence of moderate to severe depression in individuals with minimal to no depression at baseline was halved at 1 year after receiving dCBT-I treatment compared with the control group.

\section{Conclusion}

- dCBT-I can improve depression and insomnia and has a sustained antidepressant effect.

- dCBT-I is effective for preventing depression. In other words, the risk of developing depression is decreased when dCBT-I is used to treat insomnia in individuals with minimal to no depression at baseline.

2. Vedaa $\varnothing$, Hagatun $S$, Kallestad $H$, et al. Long-term effects of an unguided online cognitive behavioral therapy for chronic insomnia. J Clin Sleep Med. 2019;15(1):101-110.

dCBT-I is effective for treating insomnia in the short term; however, little is known about the long-term effectiveness of dCBT-I on sleep and daytime symptoms. Vedaa et $\mathrm{al}^{10}$ evaluated the efficacy of dCBT-I at 18 months after the intervention.

\section{Study design}

- In this randomized controlled trial (RCT), the efficacy of unguided, internetdelivered CBT-I $(\mathrm{n}=95)$ was compared with web-based patient education $(n=86)$ for patients with chronic insomnia.

- Participants were assessed at baseline, after a 9-week intervention period, and at 6-month follow-up. Participants in the internet CBT-I group were reassessed at 18 months after the intervention using online questionnaires, including the Insomnia Severity Index (ISI), Bergen Insomnia Scale (BIS), Brief Dysfunctional Beliefs and Attitudes Scale, Hospital Anxiety and Depression Scale, Chalder Fatigue Questionnaire, and sleep diaries.

\section{Outcomes}

- At 18 months, significant improvements were noted from baseline ISI and BIS scores and in levels of daytime fatigue, as well as psychological distress and beliefs about sleep.

- Sleep diary variables-including sleep onset latency, time awake during the night (wake time after sleep onset), early morning awakening, total sleep time, and sleep efficiency-showed significant improvement from baseline to 18-month follow-up (at least moderate effect size).

- Improvements were maintained from the completion of the 9-week intervention to follow-up at 18 months.

\section{Conclusion}

- Fully-automated, internet-based CBT-I is efficacious in maintaining positive effects on sleep and daytime functioning up to 18 months after completing treatment.

3. Sweetman A, Lack L, Catcheside PG, et al. Cognitive and behavioral therapy for insomnia increases the use of continuous positive airway pressure therapy in obstructive sleep apnea participants with comorbid insomnia: a randomized clinical trial. Sleep. 2019;42(12):zsz178. doi: 10.1093/sleep/ zsz178.

Comorbid insomnia and sleep apnea (COMISA) can affect a patient's ability to accept and comply with continuous positive airway pressure (CPAP) therapy. Providing adequate treatment for these patients can be challenging.

Sweetman et $\mathrm{al}^{11}$ evaluated the acceptance and use of CPAP in patients with 
obstructive sleep apnea and chronic insomnia following initial treatment with CBT-I compared with treatment as usual (TAU).

\section{Study design}

- In this RCT, 145 participants with COMISA were randomized to 4 sessions of CBT-I or TAU before starting CPAP therapy until 6 months after randomization.

- Primary outcomes were objective CPAP adherence and objective sleep efficiency at the end of 6 months.

- Secondary outcomes were CPAP acceptance/rejection, changes in sleep parameters, global insomnia severity, and daytime impairments at 6 months.

\section{Outcomes}

- The CBT-I group had higher initial CPAP acceptance and greater average nightly adherence to CPAP (61 minutes more) than the TAU group.

- Significant improvements were noted in global insomnia severity, nighttime insomnia complaints, and dysfunctional sleep-related cognitions at 6 months in the CBT-I group compared with TAU.

- No differences between the 2 groups were noted in sleep diary parameters or daytime impairments at 6 months.

\section{Conclusions}

- Patients with COMISA can benefit from receiving CBT-I before starting CPAP therapy because CBT-I can improve immediate acceptance of CPAP and may help to maintain adherence to CPAP over time.

- Patients with sleep apnea should be evaluated for comorbid insomnia, and CBT-I should be considered before starting CPAP treatment.

\section{Asarnow LD, Bei B, Krystal A, et al. Circadian preference as a moderator of depression out- come following cognitive behavioral therapy for insomnia plus antidepressant medica- tions: a report from the TRIAD study. J Clin Sleep Med. 2019;15(4):573-580.}

The Treatment of Insomnia and Depression (TRIAD) study reported the effects of combining antidepressants with CBT-I in patients with major depressive disorder (MDD) and insomnia. Asarnow et $\mathrm{al}^{12}$ examined the moderation of circadian preference in the reduction of depression and insomnia symptoms severity during the same trial.

\section{Study design}

- In this RCT, 139 participants with MDD and insomnia were treated with an antidepressant (escitalopram, sertraline, or desvenlafaxine) and randomized to 8 weeks of CBT-I or control therapy (sleep education).

- Measurements used were Composite Scale of Morningness for circadian preference (morningness vs eveningness), depression severity with the Hamilton Rating Scale for Depression, and insomnia severity using the ISI.

\section{Outcomes}

- CBT-I was effective for insomnia regardless of circadian preference.

- A smaller reduction in depression scores was noted in participants with greater evening preference.

-Depression outcomes were better among participants with evening preference if they were assigned to CBT-I vs control therapy.

- The control therapy (sleep education) was particularly ineffective in reducing depression symptoms in participants with evening preference.

\section{Conclusion}

- Individuals with MDD and insomnia and an evening preference are at an increased risk for poor response to antidepressants alone.

- Outcomes for both depression and insomnia improve if CBT-I is combined with antidepressants.

- Offering sleep education alone is not sufficient.

\section{Clinical Point \\ The CBT-I group had higher initial CPAP acceptance and greater average nightly adherence to CPAP than the TAU group}




\section{Clinical Point}

\section{Both CBT-I and sleep restriction therapy are efficacious for menopause-related insomnia, but CBT-I produces higher remission rates}

5. Drake CL, Kalmbach DA, Arnedt JT, et al. Treating chronic insomnia in postmenopausal women: a randomized clinical trial comparing cognitive-behavioral therapy for insomnia, sleep restriction therapy, and sleep hygiene education. Sleep. 2019;42(2):zsy217. doi: $10.1093 /$ sleep/zsy217.

Postmenopausal women with sleep disturbances experience higher medical and psychiatric comorbidities, and have higher alcohol consumption and stress levels than postmenopausal women with good sleep. Nonpharmacologic insomnia treatments with durable effects are imperative for postmenopausal women because they are safer than pharmacologic approaches. Although CBT-I is the recommended firstline treatment for chronic insomnia, its application in menopause-related insomnia is limited. Drake et $\mathrm{al}^{13}$ evaluated the efficacy of CBT-I in menopause-related insomnia compared with sleep restriction therapy (SRT) and sleep hygiene education (SHE).

\section{Study design}

- This RCT was conducted at a health system with 6 hospitals in Michigan.

- Postmenopausal women who met DSM-5 criteria for chronic insomnia disorder $(n=150)$ were randomized into 1 of 3 groups: SHE, SRT, or CBT-I.

- Primary outcome measures were ISI scores and sleep diaries that documented multiple sleep parameters, including sleep onset latency, wake time after sleep onset, number of awakenings in the middle of the night, time in bed, total sleep time, and sleep efficiency. These were measured at baseline, after completion of treatment, and 6 months after treatment.

\section{Outcomes}

- Both CBT-I and SRT outperformed SHE on the ISI and for most of the sleep parameters on sleep diaries immediately after treatment completion and at 6 months after treatment.
- Total sleep time was 40 to 43 minutes longer in the CBT-I group than in the SRT and SHE groups at 6-month follow-up.

- Remission rates (sleep onset latency $\leq 30$ minutes, wake time after sleep onset $\leq 30$ minutes, sleep efficiency $\geq 85 \%$ ) were significantly higher in CBT-I group (CBT-I $>$ SRT $>$ SHE).

\section{Conclusion}

- Sleep hygiene education as a standalone treatment is not useful for treating chronic insomnia.

- Both CBT-I and SRT are efficacious for menopause-related insomnia.

- CBT-I may be a better option than SRT because it produces higher remission rates and better long-term outcomes.

6. Kalmbach DA, Cheng P, Arnedt JT, et al. Improving daytime functioning, work performance, and quality of life in postmenopausal women with insomnia: comparing cognitive behavioral therapy for insomnia, sleep restriction therapy, and sleep hygiene education. J Clin Sleep Med. 2019;15(7):999-1010.

CBT-I has shown efficacy in the treatment of insomnia in postmenopausal women. In this study, Kalmbach et $\mathrm{al}^{14}$ compared 3 nonpharmacologic modalities-CBT-I, SRT, and SHE-for the treatment of menopause-related insomnia and daytime impairment.

\section{Study design}

- In this RCT, 150 participants with new peri- and post-menopausal onset or exacerbation of insomnia were randomized to 1 of 3 groups: SHE, SRT, or CBT-I.

- Participants were assessed at baseline, after treatment completion, and at 6-month follow-up using the ISI, sleep diaries, Fatigue Severity Scale, Epworth Sleepiness Scale, Work Productivity and Activity Impairment Questionnaire, and 36-item Medical Outcomes Study Short Form Health Survey. 


\section{Outcomes}

- In both the CBT-I and SRT groups, significant improvements were noted in fatigue, energy, daytime sleepiness, and work function after treatment completion and at 6-month follow-up.

- Improvements were noted in emotional well-being and resiliency to physical and emotional problems in the CBT-I group at 6 months.

- Improvements in overall general health and social functioning, less pain, and fewer hot flashes were reported by postmenopausal women who remitted from insomnia; however, these benefits were not directly related to any specific treatment modality.

\section{Conclusion}

- CBT-I and SRT are superior to SHE for improving daytime functioning, and some aspects of life quality and work productivity, in postmenopausal women with insomnia.

- CBT-I may be superior to SRT in producing larger improvements in fatigue, energy level, and daytime sleep propensity.

- CBT-I can improve emotional wellbeing and resilience to emotional problems in postmenopausal women with insomnia.

\section{Peoples AR, Garland SN, Pigeon WR, et al. Cognitive behavioral therapy for insomnia reduces depression in cancer survivors. J Clin Sleep Med. 2019;15(1):129-137.}

Depression is common in patients with cancer and is usually associated with comorbid insomnia. Depression has significant effect on treatment compliance, coping with illness, and quality of life. Peoples et $\mathrm{al}^{15}$ examined the effects of CBT-I on depression in cancer survivors.

\section{Study design}

- This was a secondary analysis of a multicenter, randomized, placebocontrolled trial that evaluated interventions for cancer survivors with chronic insomnia in which the primary outcome measure was insomnia severity.

- Cancer survivors $(n=67)$ were randomized to CBT-I plus armodafinil or placebo or to SHE plus armodafinil or placebo.

- The Patient Health Questionnaire-9 (PHQ-9) and ISI were used to measure depression and insomnia at baseline, after 7-weeks of intervention, and at 3 months postintervention.

\section{Outcomes}

- Immediately after completing the intervention, cancer survivors treated with CBT-I had significantly less depression (38\% greater improvement in depression) compared with those who received SHE (control group).

- In the CBT-I group, $23 \%$ of cancer survivors achieved a clinically important reduction (5-point reduction on PHQ-9 total score) in depression at postintervention compared with $6 \%$ of those in the control group.

- At 3 months after the intervention, only $14 \%$ of cancer survivors in CBT-I group reported depression (PHQ-9 score $>4$ ), whereas $47 \%$ of those in the control group (SHE) reported depression.

\section{Conclusion}

- CBT-I improves both depression and insomnia in cancer survivors, and the improvements are sustained at 3 months after completing treatment.

- Improvement in insomnia severity appears to mediate the positive effects of CBT-I on depression.

8. Harb GC, Cook JM, Phelps AJ, et al. Randomized controlled trial of imagery rehearsal for posttraumatic nightmares in combat veterans. J Clin Sleep Med. 2019;15(5): 757-767.

The American Academy of Sleep Medicine recommends imagery rehearsal (IR) therapy, which incorporates some components of CBT-I, for the treatment of recurrent

\section{Clinical Point CBT-I improves depression and insomnia in cancer survivors, with sustained improvement at 3 months}




\section{Clinical Point}

\section{Both imagery rehearsal and CBT-I decreased nightmare frequency and distress in veterans with PTSD}

posttraumatic stress disorder (PTSD)-related nightmares. In this study, Harb et $\mathrm{al}^{16}$ compared CBT-I plus IR to CBT-I alone for the treatment of nightmares in veterans with combat-related PTSD.

\section{Study design}

- This RCT included male and female US veterans $(n=108)$ deployed to Iraq and Afghanistan with current PTSD and recurrent nightmares related to deployment.

- Participants were randomized to 6 sessions of CBT-I plus IR or CBT-I alone.

- Primary outcome measures included frequency of nightmares and distress associated with nightmares.

\section{Outcomes}

- A significant improvement in nightmares was noted in both groups $(29 \%$ of participants showed a clinically-significant reduction in nightmare frequency and $22 \%$ of participants achieved remission).

- CBT-I plus IR was not superior to CBT-I only at postintervention and at 6-month follow-up.

\section{Conclusion}

- Both IR and CBT-I demonstrated efficacy for decreasing nightmare frequency and distress.

- Combining IR and CBT-I may not provide a synergistic advantage over CBT-I alone for treating PTSD-related nightmares in veterans.

\section{References}

1. Diagnostic and statistical manual of mental disorders, 5th ed. Washington, DC: American Psychiatric Association; 2013.

2. Morin CM, LeBlanc M, Daley M, et al. Epidemiology of insomnia: prevalence, self-help treatments, consultations, and determinants of help-seeking behaviors. Sleep Med. 2006;7(2):123-130.

3. Trauer JM, Qian MY, Doyle JS, et al. Cognitive behavioral therapy for chronic insomnia: a systematic review and metaanalysis. Ann Intern Med. 2015;163(3):191-204.

4. Wu JQ, Appleman ER, Salazar RD, et al. Cognitive behavioral therapy for insomnia comorbid with psychiatric and medical conditions: a meta-analysis. JAMA Intern Med. 2015;175(9):1461-1472.

5. van Straten $\mathrm{A}$, van der Zweerde $\mathrm{T}$, Kleiboer A, et al. Cognitive and behavioral therapies in the treatment of insomnia: a meta-analysis. Sleep Med Rev. 2018; 38:3-16.

6. Smith MT, Perlis ML, Park A, et al. Comparative metaanalysis of pharmacotherapy and behavior therapy for persistent insomnia. Am J Psychiatry. 2002;159(1):5-11.

7. Qaseem A, Kansagara D, Forciea MA, et al. Management of chronic insomnia disorder in adults: a clinical practice guideline from the American College of Physicians. Ann Intern Med. 2016;165(2):125-133.

8. Riemann D, Baglioni C, Bassetti C, et al. European guideline for the diagnosis and treatment of insomnia. J Sleep Res. 2017;26(6):675-700

9. Cheng P, Kalmbach DA, Tallent G, et al. Depression prevention via digital cognitive behavioral therapy for insomnia: a randomized controlled trial. Sleep. 2019; 42(10):zsz150. doi: 10.1093/sleep/zsz150.

10. Vedaa $\varnothing$, Hagatun $S$, Kallestad $H$, et al. Long-term effects of an unguided online cognitive behavioral therapy for chronic insomnia. J Clin Sleep Med. 2019;15(1):101-110.

11. Sweetman A, Lack L, Catcheside PG, et al. Cognitive and behavioral therapy for insomnia increases the use of continuous positive airway pressure therapy in obstructive sleep apnea participants with comorbid insomnia: a randomized clinical trial. Sleep. 2019;42(12):zsz178. doi: 10.1093/sleep/zsz178.

12. Asarnow LD, Bei B, Krystal A, et al. Circadian preference as a moderator of depression outcome following cognitive behavioral therapy for insomnia plus antidepressant medications: a report from the TRIAD study. J Clin Sleep Med. 2019;15(4):573-580.

13. Drake CL, Kalmbach DA, Arnedt JT, et al. Treating chronic insomnia in postmenopausal women: a randomized clinical trial comparing cognitive-behavioral therapy for insomnia, sleep restriction therapy, and sleep hygiene education. Sleep. 2019;42(2):zsy217. doi: 10.1093/sleep/ zsy217.

14. Kalmbach DA, Cheng $\mathrm{P}$, Arnedt JT, et al. Improving daytime functioning, work performance, and quality of life in postmenopausal women with insomnia: comparing cognitive behavioral therapy for insomnia, sleep restriction therapy, and sleep hygiene education. J Clin Sleep Med. 2019;15(7):999-1010.

15. Peoples AR, Garland SN, Pigeon WR, et al. Cognitive behavioral therapy for insomnia reduces depression in cancer survivors. J Clin Sleep Med. 2019;15(1):129-137.

16. Harb GC, Cook JM, Phelps AJ, et al. Randomized controlled trial of imagery rehearsal for posttraumatic nightmares in combat veterans. J Clin Sleep Med. 2019;15(5):757-767. 